\title{
Numerical simulation of SMA490BW steel joints with double wire welding
}

\author{
Wu Xiangyang ${ }^{1, a}$, Zhang Zhiyi ${ }^{1, a}$, He Yongpan ${ }^{2, b}$, Chen Hui ${ }^{2, b}$. \\ ${ }^{1}$ CRRC QINGDAO SIFANG Co., LTD. China, Qingdao. \\ ${ }^{2}$ Southwest Jiaotong University, School of materials science and engineering, China, Chengdu. \\ a sfxiangyangw@163.com, ${ }^{b}$ xnrpt@163.com
}

Keywords: double wire welding, numerical simulation, temperature field, stress field.

Abstract. SMA490BW steel is the main materials of making bogie, which is the key compoment of the high-speed train, and the quality of welding joint directly affects the safety of railway vehicles. In this paper SMA490BW steel jonits were welded by single wire welding and double wire welding methods. The temperature field and the stress field of the jonits were investigated by unmerical simulation. Four groups and three groups of welding and cooling process analysis step, respectively, are setted for the single wire and the double wire welding process. By adopting the technology of life and death cell, in each step to activate the corresponding welding analysis of weld bead filler. The reasonabla boundary conditions are settled, and thus the temperature fields of the two methods were observed. On based of this, the stress fields of the weld with the two welding methods were investigated. This article weld with steel SMA490BW of the bogie with double wire MAG welding method, and compared the temperature field and the stress field of the joint obtained by conventional method and double wire MAG welding method.

\section{Introduction}

Bogie is the key compoment of the high-speed train in the normal operation, and the quality of welding joint directly affects the safety of railway vehicles [1-2].With the improvement of the running speed of the trains, the higher requries are presented on the welding efficiency and quanlity. There are two methods to achieve efficient welding, one is to increase the welding speed, but the high welding speed often brings defects of incomplete penetration and undercut, the other is to improve the deposition efficiency, which leads to the heat input of welding and deformtion of the joints. Double wire melting polar gas shielded welding can significantly improve the efficiency of welding and welding quality, save material, and improve the working conditions. Xie[3] established the welding robot of double wire pulsed MAG high speed welding molten pool of mathematical model, dynamic process thought arc melting drop transition and the time constant of arc welding power source has a very close relationship, but has no obvious influence on welding wire stem elongation. $\mathrm{Xu}$ [4] compared different welding parameters of monofilament MIG welding and double wire pulsed MIG welding deposition rate, found that the efficiency and weld of double wire welding are much better than that of sigle wire welding and double wire welding reduces the bite edge caused by high speed welding. Feng[5] joined alloy steel with high strength and hardness using double wire MIG weld molten pool technology, and obtained sound welding joint, mechanical performance meeting the requirement. This article weld with steel SMA490BW of the bogie with double wire MAG welding method, and compared the temperature field and the stress field of the joint obtained by conventional method and double wire MAG welding method.

\section{Welding process}

The base metal is SMA490BW steel, and the wire for welding is JM-55II with diameter of $1.2 \mathrm{~mm}$. Table. 1 shows the chemical composition of welding stick. The size of the plate welded with single wire welding is $350 \times 150 \times 12 \mathrm{~mm}$, and the groove preparation is shown in Fig. 1. The shielding gas is $80 \% \mathrm{Ar}$ and $20 \% \mathrm{CO} 2$, and the welding process is shown in Table. 2 . 
Table.1. Chemical composition and mechanical properties of SMA490BW steel and the welding wire

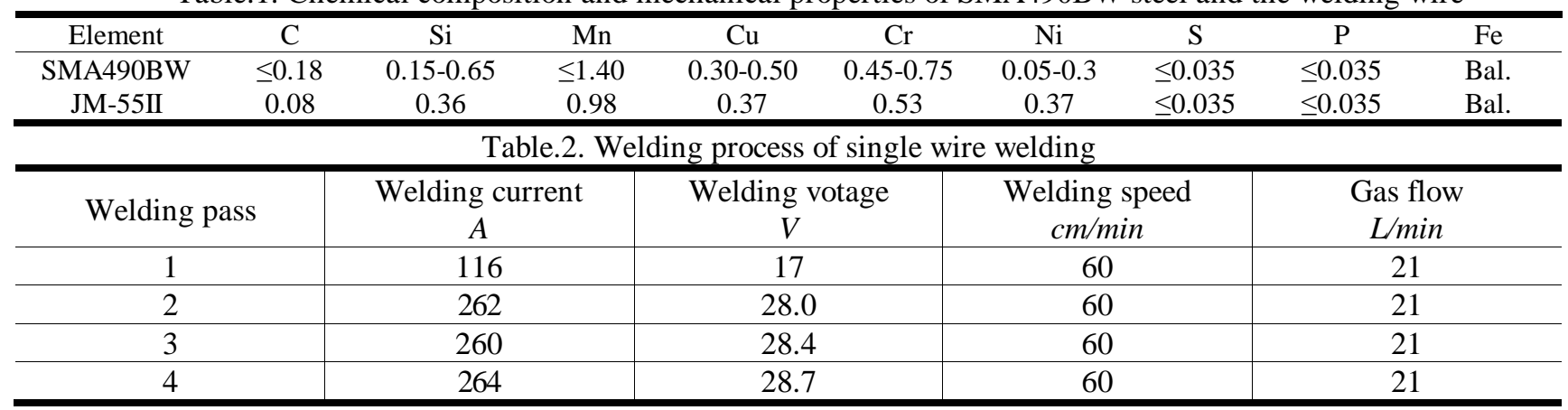

The size of the plate welded with double wire MAG welding is $350 \times 150 \times 12 \mathrm{~mm}$. The groove preparation and the shielding gas are same as the single wire welding process, which is shown in Table.3. The microstructure of joints welded with single wire welding process and double wire welding is shown in Fig.2a and Fig.2b.

Table.3. Welding process of double wire welding

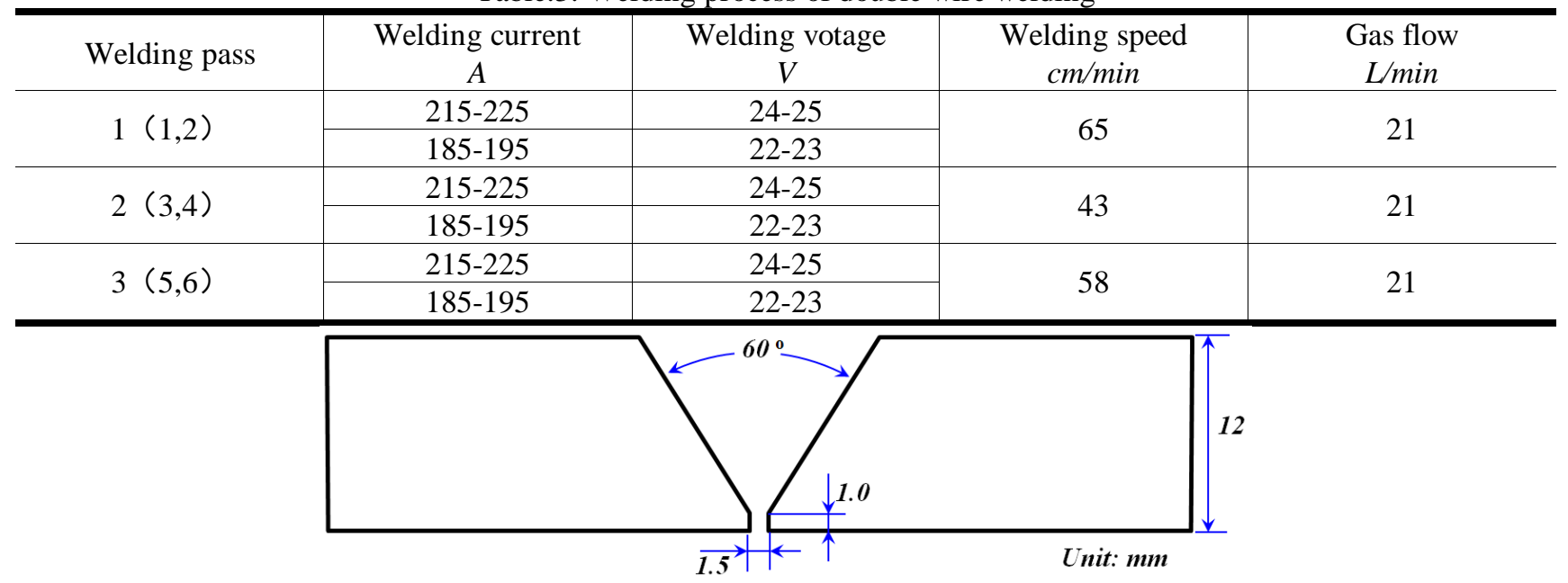

Fig.1 The groove preparation of the welding

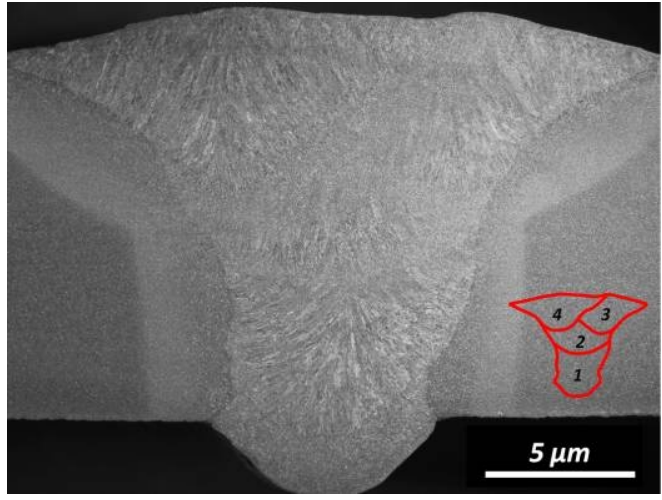

(a) Single wire welding (4 weld pass)

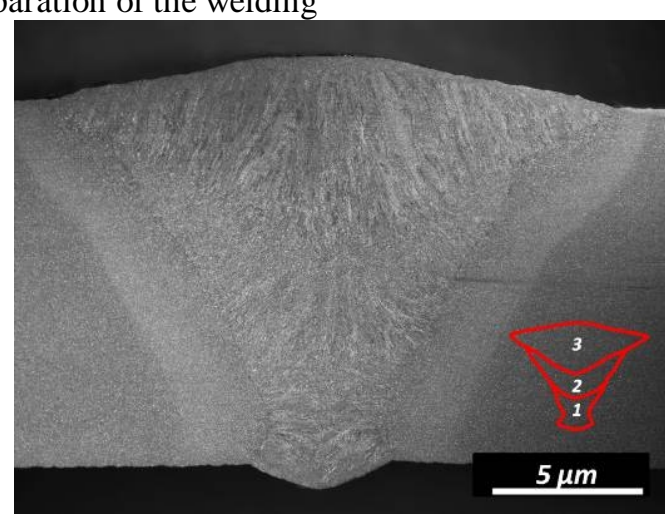

(b) Double wire welding ( 3 welding pass)

Fig. 2 The microstructure of joints welded with single wire welding process and double wire welding

\section{Mathematics Model}

\section{Weld heat source model}

The finite element model was established based on the welding test, according to the actual welding pass were set respectively based on four welding pass of monofilament butt welding process and three welding pass of double wire butt welding process. The welding heat transfer in rectangular coordinate system control method is shown in the following type,

$$
\rho(T) c_{p}(T) \frac{\partial T}{\partial t}=\frac{\partial}{\partial x}\left[k(T) \frac{\partial T}{\partial x}\right]+\frac{\partial}{\partial y}\left[k(T) \frac{\partial T}{\partial y}\right]+\frac{\partial}{\partial z}\left[k(T) \frac{\partial T}{\partial z}\right]+q
$$


Herein $\rho$ is represented density, $\mathrm{cp}$ is specific heat capacity, $\mathrm{k}$ is heat conductivity, The above three variables is a function of temperature T. $\mathrm{q}$ is input of heat source. In this article for soldering direction (vertical) $\mathrm{x}$ direction, $\mathrm{y}$ direction for lateral, $\mathrm{z}$ direction for the thickness direction. This article uses a total heat transfer coefficient of convection and radiation boundary conditions, mathematical expressions as shown below,

$$
q_{r s}=\alpha\left(T-T_{a}\right)
$$

qrs is represented total quantity of heat convection and radiation losse. A is total heat transfer coefficient of convection and radiation, $\mathrm{Ta}$ is ambient temperature, which is the function of temperature $\mathrm{T}$, meet the mathematical formula,

$$
\alpha=20+5.67^{-8} \times 0.8 \times\left(T-T_{a}\right)\left(T^{2}+T_{a}^{2}\right)
$$

For double wire welding, each welding arc can be individually using $3 \mathrm{~d}$ double ellipsoid heat source volume distribution patterns, as is shown in Fig.3, mathematical expressions as shown below,

$$
\begin{gathered}
x \geq x_{0}+v t: q_{f}(x, y, z, t)=\frac{6 \sqrt{3} f_{f} \eta U I}{\pi \sqrt{\pi} a_{f} b c} \times \exp \left(-\frac{3\left(x-x_{0}-v t\right)^{2}}{a_{f}{ }^{2}}-\frac{3\left(y-y_{0}\right)^{2}}{b^{2}}-\frac{3\left(z-z_{0}\right)^{2}}{c^{2}}\right) \\
x<x_{0}+v t: q_{r}(x, y, z, t)=\frac{6 \sqrt{3} f_{r} \eta U I}{\pi \sqrt{\pi} a_{r} b c} \times \exp \left(-\frac{3\left(x-x_{0}-v t\right)^{2}}{a_{r}{ }^{2}}-\frac{3\left(y-y_{0}\right)^{2}}{b^{2}}-\frac{3\left(z-z_{0}\right)^{2}}{c^{2}}\right)
\end{gathered}
$$

Herein $\eta$ is arc efficiency, point $(\mathrm{x} 0, \mathrm{y} 0, \mathrm{z} 0)$ is the coordinate of the center of the arc; af ar、 b、 c are, respectively, the double ellipsoid heat source volume $3 \mathrm{~d}$ shape distribution parameters (af, ar are the before and after ellipsoid parameter of distribution to the shape), ff、 fr are, respectively, the before and after the general welding heat input power in the molten pool energy distribution coefficient of the two parts, and meet the methematics fomula $\mathrm{ff}+\mathrm{fr}=2$ 。 As the condation is $\mathrm{x} \geq \mathrm{x} 0+\mathrm{vt}$, the molten pool front half ellipsoid energy distribution is used; as is $\mathrm{x}<\mathrm{x} 0+\mathrm{vt}$, the latter molten pool side half ellipsoid energy distribution is used.

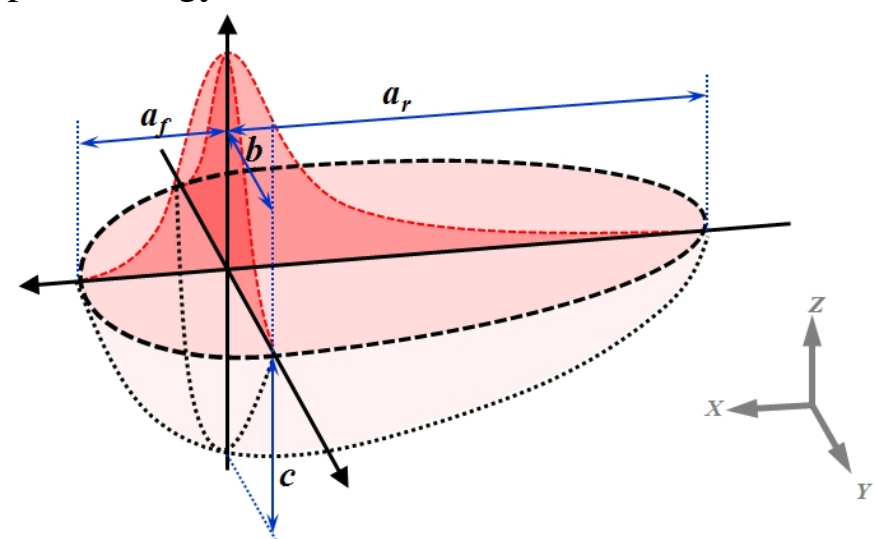

Fig. 3 double ellipsoid heat source volume 3 d shape distribution diagram

\section{Finite element model}

Finite element modes of single wire butt welding process and double wire butt welding were established on the groove preparation and the base metal size. The plates size of butt welding is $300 \times 350 \times 12 \mathrm{~mm}$, and respectively, 4 weld pass and 3 weld pass were setted based on single wire butt welding process and double wire butt welding, as is shown in Fig.4a and Fig.4b. To mesh with the finite element model, the grid size of weld area and base metal area were respectively setted as $0.8 \mathrm{~mm}$ and $5.0 \sim 10.0 \mathrm{~mm}$, and the hexahedral element were setted as transition in the middle. The model grid number of single wire butt welding is 351624 , and the number of double wire welding is 307398. The unit type of welding thermal analysis using is DC3D8, and the unit type of welding stress analysis is C3D8I. 

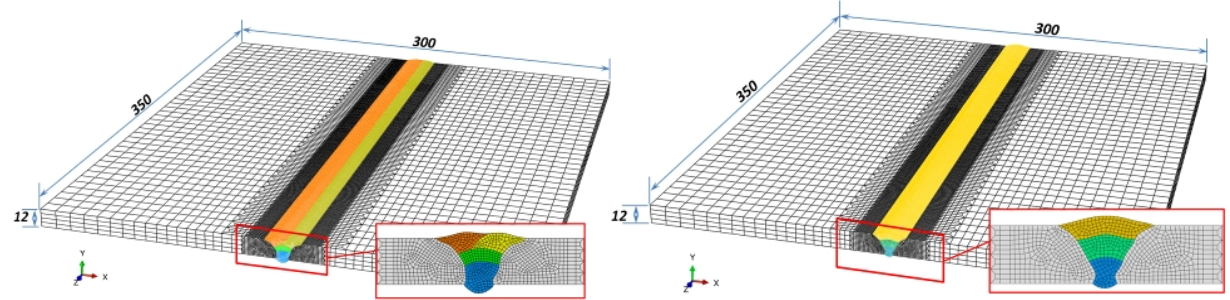

(a) single wire butt welding model (4 weld pass)（b） double wire butt welding model（3 weld pass)

Fig.4 Finite element modes of single wire butt welding process and double wire butt welding

\section{Material performance parameters}

The material performance parameters used in this article is shown in table 4 and table 5 , thermal physical properties and mechanical properties of heat resistant of SMA490BW steel were tested experimentally. Properties of weld of JM-55II materials were used as base metal.

For the molten weld matel, the metal can flow freely, and thus the strength is almost zero (elastic modulus and yield strength are seted to a minimum), And expansion of the metal flow quantity is considered as zero as that is higher than the melting temperature.

Table 4 the material performance parameters of SMA490BW steel

\begin{tabular}{c|c|c|c|c|c}
\hline $\begin{array}{c}\text { Temperature } \\
\boldsymbol{T}\left({ }^{\circ} \mathrm{C}\right)\end{array}$ & $\begin{array}{c}\text { Elasticity modulus } \\
\boldsymbol{E}(\mathrm{GPa})\end{array}$ & $\begin{array}{c}\text { Shear elasticity } \\
\boldsymbol{G}(\mathrm{GPa})\end{array}$ & Poisson's ratio & $\begin{array}{c}\text { Yield strength } \sigma_{\mathrm{s}} \\
\text { /strength of extension } \\
\boldsymbol{\sigma}_{\boldsymbol{b}}(\mathrm{MPa})\end{array}$ & $\begin{array}{c}\text { Thermal expansivity } \\
\boldsymbol{\alpha}\end{array}$ \\
\hline 20 & 201 & 75.8 & 0.33 & $446 / 603$ & - \\
\hline 80 & 199 & 75.5 & 0.33 & $395 / 518$ & $13.1 \times 10^{-6}$ \\
\hline 200 & 195 & 72.7 & 0.34 & $360 / 495$ & $14.6 \times 10^{-6}$ \\
\hline 400 & 180 & 69.6 & 0.29 & $312 / 511$ & $16.2 \times 10^{-6}$ \\
\hline 600 & 158 & 59.6 & 0.32 & $218 / 302$ & $15.3 \times 10^{-6}$ \\
\hline 800 & 105 & 39.8 & 0.33 & $88 / 109$ & $10.0 \times 10^{-6}$ \\
\hline 1000 & - & - & - & $52 / 70$ & $21.0 \times 10^{-6}$ \\
\hline
\end{tabular}

Table 5 thermophysical characteristic of SMA490BW steel

\begin{tabular}{|c|c|c|c|c|}
\hline $\begin{array}{c}\text { Temperature } \\
\left({ }^{\circ} \mathrm{C}\right)\end{array}$ & $\begin{array}{c}\text { Thermal capacity } \\
C_{p} \\
(J / g / K)\end{array}$ & $\begin{array}{l}\text { Heat conductivity coefficient } \\
\qquad \begin{array}{c}\lambda \\
\left(W \mathrm{~cm}^{-1} K^{-1}\right)\end{array}\end{array}$ & $\begin{array}{l}\text { Thermal diffusivity } \\
\qquad \begin{array}{c}\boldsymbol{a} \\
\left(\mathrm{cm}^{2} / \mathrm{s}\right)\end{array} \\
\end{array}$ & $\begin{array}{c}\text { Density } \\
\quad \boldsymbol{\rho} \\
\left(g / \mathrm{cm}^{3}\right) \\
\end{array}$ \\
\hline 32 & $4.63 \times 10^{-1}$ & $3.65 \times 10^{-1}$ & $1.01 \times 10^{-1}$ & 7.734 \\
\hline 97 & $4.59 \times 10^{-1}$ & $3.65 \times 10^{-1}$ & $1.03 \times 10^{-1}$ & 7.734 \\
\hline 200 & $5.11 \times 10^{-1}$ & $3.74 \times 10^{-1}$ & $9.41 \times 10^{-2}$ & 7.734 \\
\hline 300 & $5.68 \times 10^{-1}$ & $3.74 \times 10^{-1}$ & $8.48 \times 10^{-2}$ & 7.734 \\
\hline 400 & $6.28 \times 10^{-1}$ & $3.69 \times 10^{-1}$ & $7.55 \times 10^{-2}$ & 7.734 \\
\hline 500 & $7.35 \times 10^{-1}$ & $3.84 \times 10^{-1}$ & $6.73 \times 10^{-2}$ & 7.734 \\
\hline
\end{tabular}

\section{calculation conditions}

(1) Step analysis Settings: Four groups of welding and cooling process analysis step is setted for the single wire welding process. Three groups of welding and cooling process analysis step is setted for the double wire welding process. By adopting the technology of life and death cell, in each step to activate the corresponding welding analysis of weld bead filler.

(2) Boundary conditions: The welding structure and environmental temperature were setted to $20{ }^{\circ} \mathrm{C}$, welding and cooling analysis for each time step, all setted the current the outer surface of the welded structure (including groove and bead surface, as shown in figure 5) for convection radiation heat exchange boundary. As each welding step analysis begins, double ellipsoid heat source moved along the direction of welding volume from weld to the other end, the welding heat input reference file every weld pass were shown in table 2 and table 3). $300 \mathrm{~s}$ cooling analysis steps were setted after each welding analysis step at the end of (last step analysis cooled for $1000 \mathrm{~s}$ ).

(3) Stress analysis of boundary condition: in this paper, the stress analysis using both rigid and free constraints, as shown in figure $6 \mathrm{a}$ and $6 \mathrm{~b}$. Only three translational degrees of freedom are setted for eight nodes hexahedron. As is rigid constraints, three translational degrees of freedom of butt welding plate were fixed; Fof free constraint, constraint edge only three vertices of the different translation direction (FIG. 6 b), to avoid the rigid displacement. In this paper, the above two kinds of constraint 
conditions are calculated respectively, comparing the stress distribution under different constraint conditions.

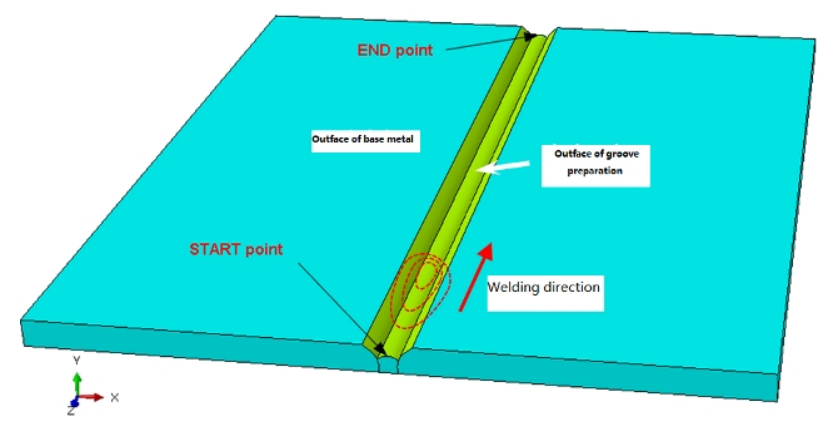

Fig.5. Temperature analysis schematic diagram

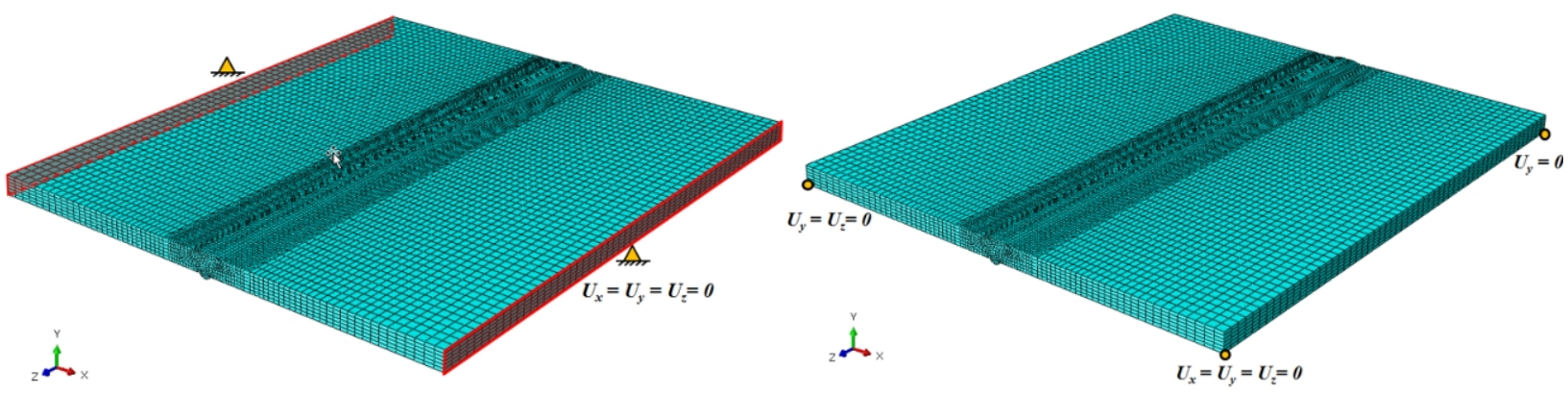

(a) rigid constraints (b) free constraint

Fig.6 Stress analysis of boundary condition

\section{The calculation results and discussion}

The weld profiles of SMA490BW were obtained based on the weld bead welding test arrangement and convective heat transfer boundary conditions is shown in Fig. 7. Single and double wire welding temperature field of welding temperature field distribution were shown in Fig.7 $a-b$ respectively (SDV1 is the node in the process of welding the highest temperature value), and the weld cross section of the double wire welding is than monofilament welding wide. The following analysis is respectively on two methods of welding thermal cycle curve specific:

(1) Single wire welding thermal cycle curve: according to the shown in figure $7 \mathrm{a}$, four node were drew of welding seam on the contour of the welding thermal cycle curve, and be as shown in figure 8 . With the increase of weld bead, interpass temperature gradually increased, the node 1\# -4\# in 1-4 weld pass peaked at temperature. Peak of each node in addition to the path of the corresponding welding thermal cycle, but also through three different levels of heat circulation, peak ranged from $600 \sim$ $1200{ }^{\circ} \mathrm{C}$.

(2) Double wire welding thermal cycle curve: according to the Fig.7b, the three node was extracted on the weld profile of welding thermal cycle curve, and the thermal cycle curve was shown in Fig $8 \mathrm{~b}$. With the increasing of the welding interlayer temperature every time, surface temperature between layers was controlled under $250 \mathrm{oC}$ because of the large heat dissipation compared with single wire welding. in addition to the corresponding peak of bead welding thermal cycle, 1\# -4\# nodes were heated by two adjacent weld heat circulation, the peak varied from $600 \sim 1500{ }^{\circ} \mathrm{C}$, which was slightly higher than single wire welding.

Compared with two kinds of welding methods, the temperature of weld area was more uniform because the double wire welding heating source were setted side by side. As is shown in figure 9 a and $\mathrm{b}$, for the two kinds of welding methods, nine node were extracted from the temperature cycle curve of the weld center $8 \mathrm{~mm}$ distance to the center of the position. For single wire welding, along the horizontal $8 \mathrm{~mm}$ of distance peak temperature dropped under $800 \mathrm{oC}$. For double wire welding, the temperature gradient of the weld was small, and the cooling speed is slow, $t 8 / 5$ significantly increased. 


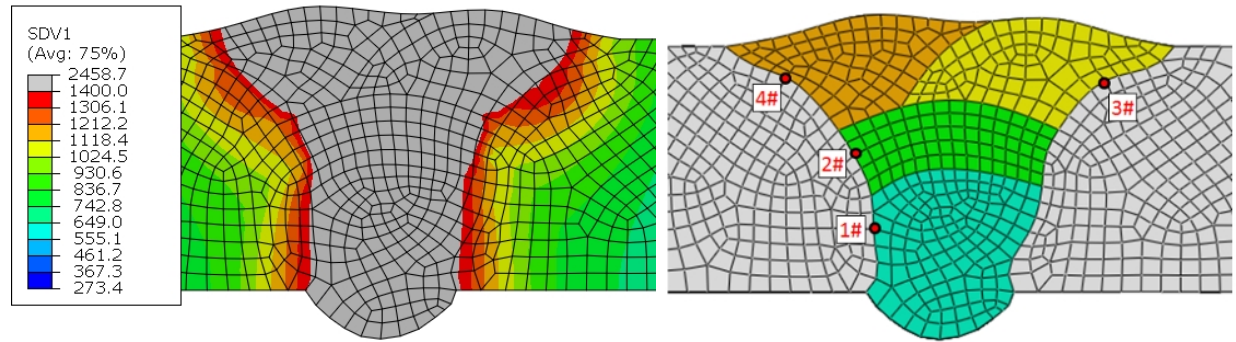

(a) Temperature field simulation of single wire welding

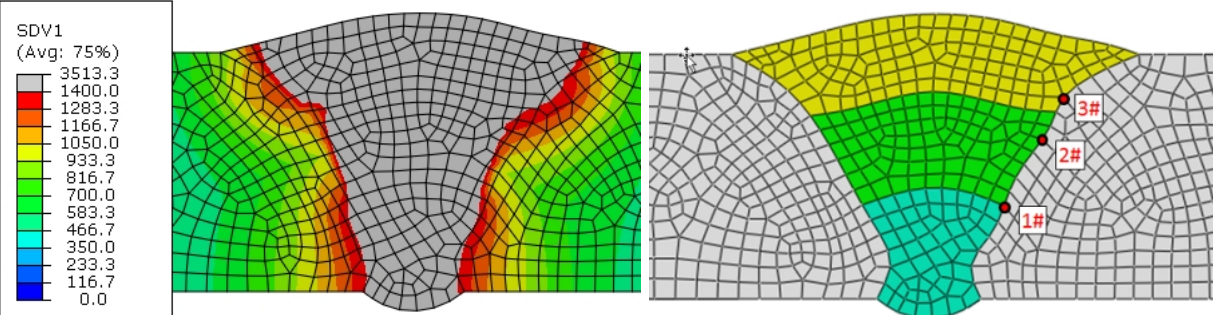

(b) Temperature field simulation of double wire welding

Fig.7 weld profile graphs based on double ellipsoid heat source simulation
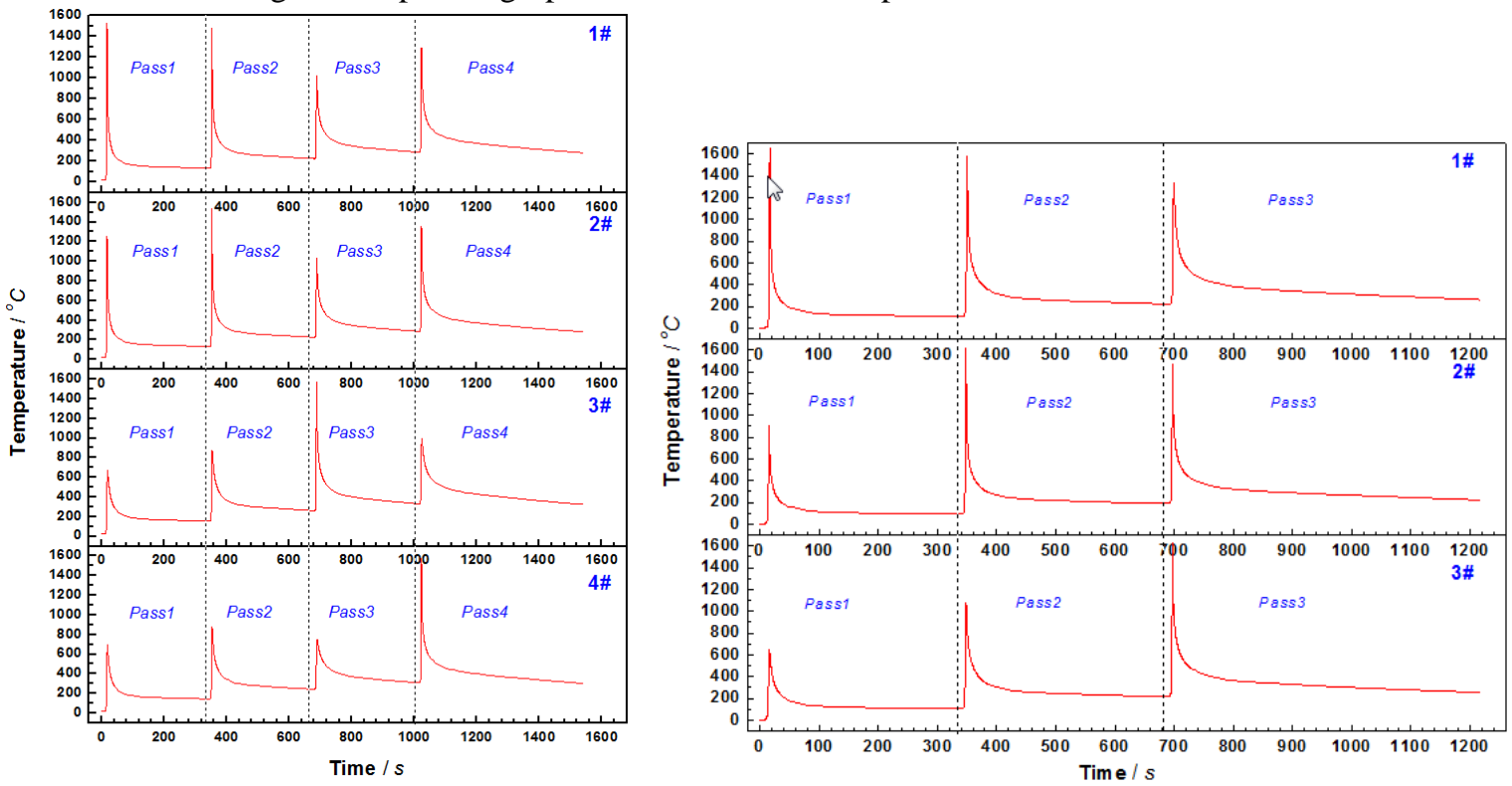

(a) Nodes on single wire welding thermal cycle curve (b) Nodes on double wire welding thermal cycle curve

Fig. 8 the welding thermal cycle curve based on double ellipsoid heat source simulation
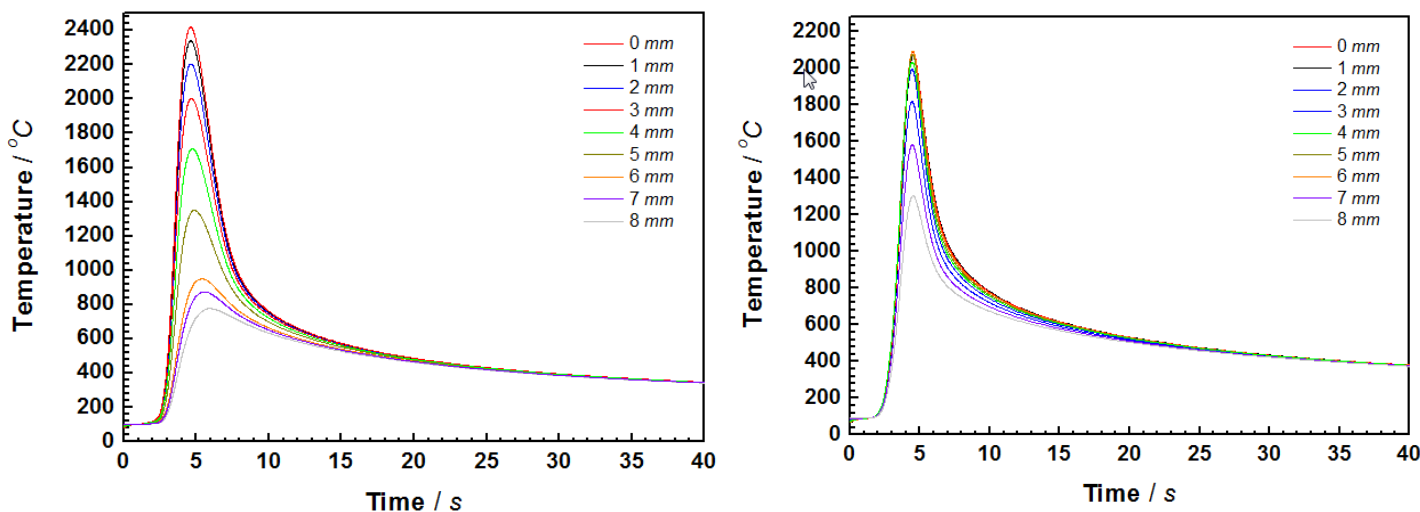

(a) Peak change of thermal cycle curve with single wire welding (b) Peak change of thermal cycle curve with double wire welding

Fig.9 Thermal cycle curve of different distances from the center 


\section{Conclusions}

Four groups and three groups of welding and cooling process analysis step, respectively, are setted for the single wire and the double wire welding process. By adopting the technology of life and death cell, in each step to activate the corresponding welding analysis of weld bead filler. The reasonabla boundary conditions are settled, and thus the temperature fields of the two methods were observed. single wire welding thermal cycle curve shows that peak of each node in addition to the path of the corresponding welding thermal cycle, but also through three different levels of heat circulation, peak ranged from $600 \sim 1200{ }^{\circ} \mathrm{C}$. Double wire welding thermal cycle curve shows that the peak varied from $600 \sim 1500{ }^{\circ} \mathrm{C}$, which was slightly higher than single wire welding.

\section{References}

1. Jiang Xishan, Zhao Han. Quick manual of microscopic fracture of steel[M].Beijing : China Machine Press, 2010.(in Chinese)

2. Bai Zhifan, Li Guizhong, Wang Chao. Mechanical propertiee and microstructure of weld of the bogie of the high-speed train[J]. Journal of Jilin University. 2012, 42(1): 208-211. (in Chinese)

3. Jie Shengmian. Research on robot double wire pulsed MAG high speed welding molten pool and coordinated control mode drop transition behavior [D].Guangzhou: South China University of Technology. 2012. (in Chinese)

4. Xu Furong, YaoTao, Yang lijun. Welding process characteristics and experimental analysis of double wire pulsed MIG welding[J]. Automation \& Instrumentation, 2012, 164(6):183-185. (in Chinese)

5. Feng Rihai, Wang Kehong, Wang Jianping. Hard alloy steel with high strength and high double wire welding technology and joint organization performance [J]. Welding institution, 2007, 28(11):98-100. (in Chinese) 